\title{
Geriatric hip fracture clinical pathway: the Hong Kong experience
}

\author{
T. W. Lau • F. Leung • D. Siu • G. Wong • K. D. K. Luk
}

Received: 18 August 2010 / Accepted: 23 August 2010

(C) The Author(s) 2010. This article is published with open access at Springerlink.com

\begin{abstract}
Geriatric hip fracture is one of the commonest fractures in orthopaedic trauma. There is a trend of further increase in its incidence in the coming decades. Besides the development of techniques and implants to overcome the difficulties in fixation of osteoporosis bone, the general management of the hip fracture is also very challenging in terms of the preparation of the generally poorer pre-morbid state and complicate social problems associated with this group of patients. In order to cope with the increasing demand, our hospital started a geriatric hip fracture clinical pathway in 2007. The aim of this pathway is to provide better care for this group of patients through multidisciplinary approach. From year 2007 to 2009, we had managed 964 hip fracture patients. After the implementation of the pathway, the pre-operative and the total length of stay in acute hospital were shortened by over 5 days. Other clinical outcomes including surgical site infection, 30 days mortality and also incidence of pressure sore improved when compared to the data before the pathway. The rate of
\end{abstract}

T. W. Lau $(\bowtie) \cdot$ F. Leung $\cdot$ K. D. K. Luk

Department of Orthopaedics and Traumatology,

Queen Mary Hospital, The University of Hong Kong,

102, Pokfulam Road,

Hong Kong, Hong Kong SAR, People's Republic of China

e-mail: catcherlau@hotmail.com

D. Siu

Department of Medicine, Queen Mary Hospital,

The University of Hong Kong,

102, Pokfulam Road,

Hong Kong, Hong Kong SAR, People's Republic of China

G. Wong

Department of Anaesthesiology, Queen Mary Hospital,

The University of Hong Kong,

102, Pokfulam Road,

Hong Kong, Hong Kong SAR, People's Republic of China surgical site infection was $0.98 \%$, and the 30 days mortality was $1.67 \%$ in 2009 . The active participation of physiotherapists, occupational therapists as well as medical social workers also helped to formulate the discharge plan as early as the patient is admitted. In conclusion, a well-planned and executed clinical pathway for hip fracture can improve the clinical outcomes of the geriatric hip fractures.

Keywords Clinical outcomes · Clinical pathway - Geriatric hip fracture $\cdot$ Multidisciplinary

\section{Introduction}

Geriatric hip fracture is a worldwide problem. It imposes a great burden on the resources used in health-care system nowadays [1-3]. The problem is ever increasing in Hong Kong as well. The total number of hip fractures operated in government hospital rises from around 4,000 patients in 2006 to around 4,500 patients in 2009. The mortality rate of these patients is also significant. The 1 year mortality can be up to $33 \%$ [4]. Post-operative complications like chest infection and heart failure are also shown to increase mortality rate [4]. In view of these, many centres would like to improve their clinical outcomes, and at the same time, to reduce the costs. It was shown to be effective by a multidisciplinary approach or the use of critical clinical pathway $[5,6]$.

\section{Background}

In year 2006, the need of reforming the hip fracture management becomes one of the primary objectives in our department in view of the increasing number of hip 
fractures and the lack of systematic approach to this problem. Various clinical pathways from other parts of the world were reviewed. There were good and bad points about individual pathway. Nevertheless, the most important consideration is that the clinical pathway should be suitable to the uniqueness and culture of the Hong Kong medical system. In late 2006, we decided to call for a meeting to gather all the appropriate professions to start the first review of our geriatric hip fracture management. Besides the medical profession, the hospital administration provided full support to the development of this clinical pathway.

\section{Problems identification}

The aim of our clinical pathway is to standardise the management of geriatric hip fracture so that these patients can be taken care of effectively and promptly when they are managed by the frontline staff. The goal is to improve patients' clinical outcomes with good quality of care. It should also bring reduction of the cost of care. It should be stressed that the pathway should not be considered as the golden rule. Individual clinical assessment and management should be respected as different patients have different needs. However, the pathway can help us facilitate our thinking and thus our clinical management.

One of the most tedious but important thing before the pathway started was to identify the problems and determine the solutions. During this process, some historical data were collected before we could proceed. In year 2006, the average pre-operative length of stay is 6.1 days which was considered now as a totally unacceptable figure. Although there is still controversy on the timing of surgery relating to the outcomes of the patients, the common consensus is to operate these patients once they are medically optimised. These fractures should be operated as soon as possible [4, 7-11]. The pre-operative length of stay should be kept to within $48 \mathrm{~h}$. This was quoted as a national guideline by the British Orthopaedic Association [12]. Therefore, the improvement of our pre-operative length of stay is set as our first priority. On the other hand, the 2006 data on post-operative length of stay in acute hospital was 6.6 days. The average length of stay in rehabilitation hospitals was 40 days.

One of the reasons in delay of pre-operative workup is the lack of awareness and the general attitude on how these patients are prepared for surgeries. In Hong Kong, the hip fracture patients are most of the time transferred to our hospital within 4-6 h. At present, over $95 \%$ of the hip fractures are fixed surgically. All of them should be prepared for operation as soon as they arrived in the accident and emergency department. In order to speed up the pre-operative preparation, there should not be any delay, wastage of time nor resources. After our first meeting, several problems were identified.

1. There are no standard pre-operative X-ray assessments in the accident and emergency department.

2. There is no standard pre-operative workup of the patients when they are admitted to the orthopaedic wards

3. Unnecessary and ineffective consultations of medical problems are often the main cause of delay. One of the most common one is cardiac assessment.

4. Level of expertise varies in hip fracture surgeries, and these surgeries were commonly done by junior surgeons without proper supervision.

5. Immediate post-operative clinical management and mobilisation varies according to the individual doctors' experience.

6. No good communication between medical staff with patient and patient's family about the management plan and outcome of the hip fractures. This resulted in misunderstanding and over expectation. Commonest misconceptions include patient transferral to rehabilitation hospital till stitches were removed or patient was discharged from rehabilitation hospital when they achieve pre-injury level walking ability.

7. Social problems are known, probably the commonest, reason to cause delay in rehabilitation and discharge. Yet the intervention is not active and early enough. There is also lack of communication between medical social workers of acute and rehabilitation hospitals.

\section{Implementation of clinical pathway}

Aiming to tackle all these problems, the geriatric clinical pathway was set up in the 2007. However, it is expected to bring big change to every aspect of the system. The support of various leaders in different departments is required, for example, anaesthesia, physician, nurses, physiotherapist, occupational therapist and medical social workers. We all agreed that the clinical pathway should be a simple and easy way to allow the frontline doctors, nurses and paramedical staff to follow. It is important to smooth out the work flow of both the acute and rehabilitation hospitals without increasing the burden of the daily clinical work.

A pilot run is a must before the full implementation to ensure smooth running and adjustment of the staff.

\section{Multidisciplinary approach}

One of the key points to the future success of the pathway is the employment of multidisciplinary approach. An orthopaedic specialist should be the clinical champion to lead the clinical pathway. The other professions involved in the group include 
the nurse, the physiotherapist, the occupational therapist and the medical social worker from both the acute and the rehabilitation hospitals. The working group also involved the anaesthetist, the cardiologist and also some of the non-government organisations. Another key element in the pathway was a specialty orthopaedic nurse as the project manager who was responsible for the audit and data collection.

\section{Pilot run}

A pilot run is essential for the future smooth running of the pathway. It was carried out for 3 months. The results were then evaluated and any problems reviewed. At the beginning, the change was considered by some of the colleagues as difficult. However, as the pilot run was finished, we found out that the pathway actually sped up the whole system. Both the clinical champion and the case manager had to monitor the progress regularly to ensure guidelines were followed. After the 3 months trial, the pre-op length of stay had already showed significant improvement by 2 days. Many colleagues, including some of the orthopaedic colleagues, the anaesthetists and physicians, initially remained sceptical, but later became more acceptable to the change.

\section{The Clinical Pathway (Table 1)}

a. Queen Mary Hospital

As the target problems are identified, these problems have to be solved to ensure smooth management of the hip fracture patients. The improvement is divided into several phase.

The pre-admission phase:

Besides the fracture hip X-rays, the pre-operative pelvic X-ray and chest X-ray should be a standard. They should be available when the patient is transferred from the accident and emergency department to the orthopaedic ward.

The pre-operative phase:

This is an important and critical phase. A standard series of basic blood investigations, including the complete blood count, liver and renal function test, clotting profile as well as type and screen of blood group, are done immediately $24 \mathrm{~h}$ a day. An electrocardiogram is also obtained immediately. The patients will be prepared for operation next day. Pain is controlled with adequate analgesics. The patients and the patients' relatives are informed and consented about the operative procedures. One of the important aspects in this phase is that the nurses will explain to the patients and their families about the management plan and the estimated length of stay in both the acute hospital and rehabilitation hospital. Therefore, the patients can have a good estimation of what they will undergo in the coming few weeks time. This is particularly important in building up the rapport and it also facilitates the future placement issues.

The post-operative phase:

As post-operative delirium is well documented to be related to inadequate pain control [13], these patients are given oral analgesics regularly together with intra-muscular injections. They are assessed immediately by physiotherapy, occupational therapy for their mental state and rehabilitation potential. These parameters are important information for the rehabilitation staff in the convalescence hospital, it could help to relieve their time for reassessment and thus speed up the process of rehabilitation. Besides the assessment, the patients are also supervised to perform breathing exercise as well as walking exercise once the drains are removed. Drains are usually removed the next day. Any indwelling catheters are removed as soon as the patients are able to ambulate. The medical social workers will also reassess the patients to formulate and confirm the discharge plan. These data are recorded and transferred with the patients to the convalescence hospitals.

b. Convalescence hospitals

Once the patients are transferred, the rehabilitation starts immediately. The rehabilitation is started according to the surgeon's advice and the colleagues' assessment. The mental state test, the Mini Mental State Examination (MMSE) and the activities of daily living, the Modified Barthel Index (MBI), are reassessed to monitor the rehabilitation progress. The discharge plan was followed base on the recommendations given by the medical social worker during the acute hospital stay. Any orthopaedic issue will be addressed by the rehabilitation specialist. On the other hand, the geriatric comorbidities will be managed by the geriatricians in the convalescence hospital. With this comprehensive approach, the re-admission rate back to acute hospital is kept to a very low rate and was decreasing in the last few years.

\section{Problems addressed}

a. Last minute cancellation

As many of the previous hip surgeries are cancelled in the last minute, this is commonly due to the lack of coordination and communication between orthopaedic surgeons, anaesthetists and physicians. The two main medical reasons are chest infection and undiagnosed cardiac problems. 
Table 1 Care map of the geriatric hip fracture clinical pathway

\begin{tabular}{|c|c|c|c|c|}
\hline \multicolumn{4}{|l|}{ Queen Mary Hospital } & \multirow{2}{*}{$\begin{array}{l}\text { Convalescence Hospitals } \\
\text { Rehabilitation }\end{array}$} \\
\hline & Pre-operative period & Operation day & $\begin{array}{l}\text { Post-operative period in } \\
\text { acute hospital }\end{array}$ & \\
\hline \multicolumn{5}{|l|}{ Problems } \\
\hline Pain Control & $\begin{array}{l}\text { Oral and or intramuscular } \\
\text { analgesics }\end{array}$ & $\begin{array}{l}\text { Intramuscular } \\
\text { analgesics }\end{array}$ & $\begin{array}{l}\text { Oral and or intramuscular } \\
\text { analgesics }\end{array}$ & Analgesics \\
\hline Limb condition & $\begin{array}{l}\text { Circulation and } \\
\text { neurology }\end{array}$ & $\begin{array}{l}\text { Circulation and } \\
\text { neurology }\end{array}$ & Circulation and neurology & Circulation and neurology \\
\hline $\begin{array}{l}\text { Poor control medical } \\
\text { problems }\end{array}$ & $\begin{array}{l}\text { Consult medical if poor } \\
\text { control medical co- } \\
\text { morbidities }\end{array}$ & $\begin{array}{l}\text { Medical co- } \\
\text { morbidities } \\
\text { controlled }\end{array}$ & $\begin{array}{l}\text { Medical co-morbidities } \\
\text { controlled }\end{array}$ & Geriatricians involvement \\
\hline Post-op complication & & & $\begin{array}{l}\text { Detect and rectified post-op } \\
\text { complications }\end{array}$ & $\begin{array}{l}\text { Wound care; Fracture stability } \\
\text { monitoring }\end{array}$ \\
\hline $\begin{array}{l}\text { Awareness of } \text { ALOS }^{\mathrm{a}} \\
\text { general pre-op } \\
\text { operation and post- } \\
\text { operative care }\end{array}$ & $\begin{array}{l}\text { Patient and family } \\
\text { education including } \\
\text { consent }\end{array}$ & $\begin{array}{l}\text { Patient (and } \\
\text { family) agree } \\
\text { for OT }\end{array}$ & $\begin{array}{l}\text { Patient and family } \\
\text { education including } \\
\text { ALOS }\end{array}$ & $\begin{array}{l}\text { Family interview; Regular nurse } \\
\text { follow-up }\end{array}$ \\
\hline Discharge planning & & & & $\begin{array}{l}\text { Discharge planning based on } \\
\text { physiotherapy, occupational therapy, } \\
\text { MSW assessment, patient and family } \\
\text { communication }\end{array}$ \\
\hline Goals & $\begin{array}{l}\text { Pain control and pre-op } \\
\text { work-up }\end{array}$ & $\begin{array}{l}\text { Ready for } \\
\text { surgery }\end{array}$ & $\begin{array}{l}\text { Pain control, Complication } \\
\text { detection, Ambulation } \\
\text { and preparation to } \\
\text { convalescence }\end{array}$ & $\begin{array}{l}\text { Wound care; Physical rehabilitation and } \\
\text { formulate discharge plan }\end{array}$ \\
\hline
\end{tabular}

\begin{tabular}{|c|c|c|c|c|}
\hline \\
\hline $\begin{array}{l}\text { Staff Tasks } \\
\text { Nutrition }\end{array}$ & $\begin{array}{l}\text { Diet at tolerance/Special } \\
\text { diet }\end{array}$ & $\begin{array}{l}\text { Fast } 8 \text { hours } \\
\text { before } \\
\text { operation }\end{array}$ & $\begin{array}{l}\text { Diet at tolerance/Special } \\
\text { diet }\end{array}$ & Diet at tolerance/Special diet \\
\hline Monitor & $\begin{array}{l}\text { Blood pressure/Pulse/ } \\
\text { Temperature }\end{array}$ & $\begin{array}{l}\text { Blood } \\
\text { pressure/ } \\
\text { Pulse/ } \\
\text { Temperature }\end{array}$ & $\begin{array}{l}\text { Blood pressure/Pulse/ } \\
\text { Temperature }\end{array}$ & Blood pressure/Pulse/Temperature \\
\hline Pain control & $\begin{array}{l}\text { Oral and/or intramuscular } \\
\text { analgesics }\end{array}$ & $\begin{array}{l}\text { Oral and/or } \\
\text { intramuscular } \\
\text { analgesics }\end{array}$ & $\begin{array}{l}\text { Oral and/or intramuscular } \\
\text { analgesics }\end{array}$ & Oral analgesics \\
\hline General Investigations & $\begin{array}{l}\text { CBP, L/RFT, astrup, } \\
\text { T\&S, ECG, CXR }\end{array}$ & & $\begin{array}{l}\text { CBP, L/RFT; Transfuse } \\
\text { blood if indicated }\end{array}$ & CBP, L/RFT, CXR if indicated \\
\hline Special investigations & $\begin{array}{l}\text { XR Pelvis and hip } \\
\text { available }\end{array}$ & & $\begin{array}{l}\text { XR Pelvis and hip; septic } \\
\text { workup if high fever after } \\
\text { day } 3\end{array}$ & $\begin{array}{l}\text { XR Pelvis and hip; Doppler ultrasound } \\
\text { if indicated }\end{array}$ \\
\hline Consultation & $\begin{array}{l}\text { Medical or anaesthetist } \\
\text { consultation if indicated }\end{array}$ & & $\begin{array}{l}\text { Medical consultation for } \\
\text { follow up monitoring }\end{array}$ & Geriatricians consultation if indicated \\
\hline Medication & $\begin{array}{l}\text { Withhold warfarin; } \\
\text { Vitamin K } 10 \text { mg daily }\end{array}$ & $\begin{array}{l}\text { Cephazolin } \\
1 \text { gm } \\
\text { intravascular } \\
\text { on induction }\end{array}$ & $\begin{array}{l}\text { Resume Warfarin if } \\
\text { haemostasis achieved }\end{array}$ & $\begin{array}{l}\text { Resume Warfarin if haemostasis } \\
\text { achieved }\end{array}$ \\
\hline $\begin{array}{l}\text { Thromboemobolism } \\
\text { prevention }\end{array}$ & $\begin{array}{l}\text { Prophylactic } \\
\text { subcutaneous } \\
\text { enoxaparin before } \\
\text { operation in indicated } \\
\text { subjects }^{\mathrm{c}}\end{array}$ & $\begin{array}{l}\text { Enoxaparin } \\
\text { without } \\
24 \text { hours } \\
\text { before } \\
\text { surgery }\end{array}$ & $\begin{array}{l}\text { Prophylaxis continued till } \\
\text { patient mobilize }\end{array}$ & $\begin{array}{l}\text { Prophylaxis stopped if patient mobilize } \\
\text { well }\end{array}$ \\
\hline Physiotherapy & Pre-op $\mathrm{MBI}^{\mathrm{c}}$ assessment & & $\begin{array}{l}\text { Post-op chest and limb } \\
\text { assessment; walking } \\
\text { exercise as soon as possible }\end{array}$ & $\begin{array}{l}\text { Rehabilitation potential assessment and } \\
\text { mobility training; MBI assessment }\end{array}$ \\
\hline Occupational therapy & $\begin{array}{l}\text { Pre-op assessment on } \\
\text { mental state, } \mathrm{ADL}^{\mathrm{e}} \text { and } \\
\text { home environment }\end{array}$ & & $\begin{array}{l}\text { Post-op assessment on } \\
\text { mental state, ADL and } \\
\text { home environment }\end{array}$ & $\begin{array}{l}\text { ADL, mental state, home environment } \\
\text { assessment }\end{array}$ \\
\hline
\end{tabular}


Table 1 (continued)

\begin{tabular}{|c|c|c|c|c|}
\hline \multicolumn{4}{|l|}{ Queen Mary Hospital } & \multirow{2}{*}{$\begin{array}{l}\text { Convalescence Hospitals } \\
\text { Family interview for discharge } \\
\text { planning; Care provider arrangement; } \\
\text { Discharge plan proceed }\end{array}$} \\
\hline $\begin{array}{l}\text { Medical Social } \\
\text { Worker (MSW) }\end{array}$ & Referral & & $\begin{array}{l}\text { Referral and assessment; } \\
\text { Preliminary planning }\end{array}$ & \\
\hline Patient activity & Uninjured limb exercise & $\begin{array}{l}\text { Uninjured } \\
\text { limb exercise }\end{array}$ & $\begin{array}{l}\text { Breathing and walking } \\
\text { exercise }\end{array}$ & $\begin{array}{l}\text { Walking exercise; Living environment } \\
\text { simulation }\end{array}$ \\
\hline Foley care & Foley care if needed & $\begin{array}{l}\text { Foley care if } \\
\text { needed }\end{array}$ & $\begin{array}{l}\text { Foley care if needed; } \\
\text { remove foley as soon as } \\
\text { possible }\end{array}$ & Foley care if needed \\
\hline Trauma list notification & $\begin{array}{l}\text { Put on trauma list if } \\
\text { patient ready }\end{array}$ & $\begin{array}{l}\text { Trauma list } \\
\text { available }\end{array}$ & & \\
\hline $\begin{array}{l}\text { Education patient and } \\
\text { family }\end{array}$ & $\begin{array}{l}\text { Fall protocol, See } \\
\text { relatives for consent, } \\
\text { ALOS }\end{array}$ & $\begin{array}{l}\text { See relatives } \\
\text { for consent, } \\
\text { ALOS }\end{array}$ & $\begin{array}{l}\text { Education on post-op care, } \\
\text { rehabilitation plan and } \\
\text { convalescence transferral }\end{array}$ & $\begin{array}{l}\text { See relatives to arrange plan for } \\
\text { discharge; care provider arrangement }\end{array}$ \\
\hline Discharge/Transfer & & & $\begin{array}{l}\text { To convalescence hospital } \\
\text { once patient medically } \\
\text { stabilized }\end{array}$ & Discharge as planned \\
\hline
\end{tabular}

${ }^{a} A L O S$ Average Length Of Stay

${ }^{\mathrm{b}}$ CBP Complete Blood Picture; L/RFT Liver/Renal Function Test; T\&S Type \& Screen; ECG Electrocardiogram; CXR Chest X-Ray

${ }^{\mathrm{c}}$ Caucasians and previous history of deep vein thrombosis

${ }^{\mathrm{d}}$ MBI Modified Barthel Index

${ }^{\mathrm{e}} A D L$ Activities of Daily Living

i. Chest infection

It has been repeatedly stressed that infective condition such as chest infection or urinary tract infection is not a contra-indication to anaesthesia [12]. The most appropriate management of these infective conditions is to mobilise these patients early and then treat accordingly. However, this concept is not known to many of the anaesthetist or even among the orthopaedic colleagues. The advantage of early surgeries is well documented $[6,11,12]$. This information is discussed with the anaesthetist, physicians as well as junior orthopaedic surgeons as well. Patients benefited from early surgeries and unnecessary delay is avoided.

ii. Incidental systolic heart murmur

Many of the geriatric hip fracture patients commonly have three or more comorbidities. Among these patients, anaesthesia is mostly spinal anaesthesia. However, one of the contraindication to spinal anaesthesia is severe aortic stenosis. This is usually diagnosed by clinical examination. However, it is usually not picked up by the surgeons until the patients are assessed by the anaesthetists. In the past, once the murmur was picked up, these patients would need a formal cardiologist assessment. The process may take more than 2 days due to the consultation time and arrangement of echocardiogram. Therefore, in order to improve on this aspect, we cooperate with a cardiologist. Once there is any doubt in the cardiology fitness for the operation, the cardiologist will be contacted by phone with the electrocardiogram and a brief history faxed to him. A cardiac assessment would then be arranged within the same day. The operation will be arranged in the afternoon to allow time for morning cardiac assessment. The anaesthetist can also have a detail communication with the cardiologist after the assessment (Fig. 1). This new arrangement not only decreases the cancellation rate but also improves the anaesthetic risk because the anaesthetist and the cardiologist can have a channel to communicate.

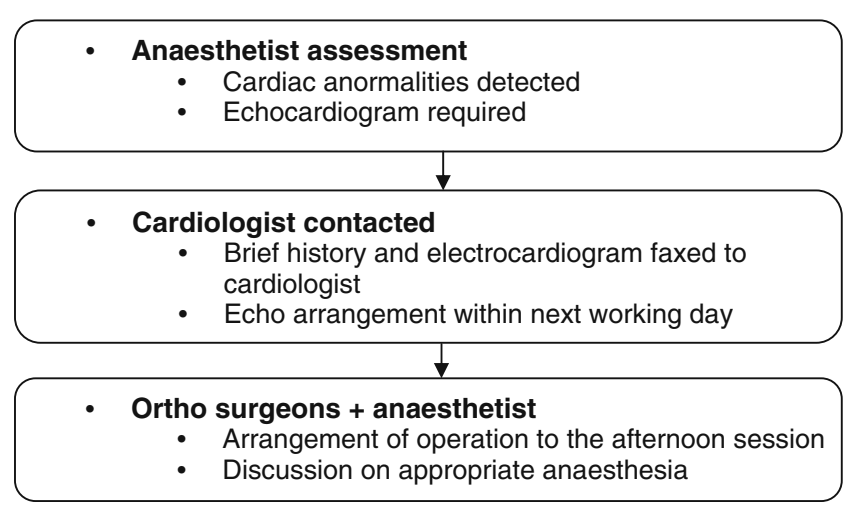

Fig. 1 Flowchart of management of pre-operative complicate cardiac conditions 
b. Special medications:

i. Patients on warfarin

In Chinese population, patients on warfarin are much less frequent because of the less incidence of deep vein thrombosis. However, patients with cardiac arthymias or coronary stents are still commonly prescribed with warfarin. These patients have two problems. Firstly, their cardiac reserves are doubtful. Cardiac consultation is common. The second problem is the warfarin itself. This poses a big problem to anaesthetist and orthopaedic surgeons because of the contraindication to spinal anaesthesia and risk of excessive bleeding respectively. Therefore, all patients on warfarin, when they are admitted, the warfarin will be stopped if not contraindicated. Oral vitamin $\mathrm{K}$ was also given to reverse the effect of warfarin. The INR can be optimised to less than 1.5 in usually less than $48 \mathrm{~h}$.

ii. Clopidogrel (plavix)

This is also one of the common medications that were given to patients with previous history of stroke or stent. The half life of it is around 7 days. Therefore, the clopidogrel should be stopped for 7 days before elective hip or knee replacement surgeries. However hip fracture surgeries are not like joint replacement surgeries. The benefits of early stabilisation of these fractures certainly outweight the risks of asking the patients to stay in bed for 7 days $[12,14]$. Hence, after communication with the anaesthetist, the patients can now proceed to surgeries once they are fit.

c. Utilisation of the operating theatre

All our geriatric hip fractures are now operated within day time. No hip fractures are operated in the middle of the night. This practise has two benefits. One is that the surgeries are likely to be supervised by a senior orthopaedic surgeon. The time of surgery is shorter and more predictable. The anaesthetist thus has a better estimation of blood loss and risks of anaesthesia. The complication rate of the fracture fixation is also lower. This certainly decreases the incidence of revision surgeries. Secondly, the orthopaedic surgeons like the new system. It ensures that they can have the operation done in the day time. Sometimes these fractures are difficult to treat because of osteoporosis and fracture comminution. When help is needed, it can be found easily.

d. Discharge planning on admission day

One of the reasons why the hip fracture patients stay in the hospital for long period of time is the difficulty of discharging the patients from convalescence hospital. This may be due to various reasons:

i. Unrealistic expectations

Many patients and their families expect the hip fracture patients can resume their premorbid walking ability and sometimes even better than before because of the "fixation" of "weak hip". However, the reality is that most of these patients will suffer a certain degree of disability and loss of function afterwards [15]. Therefore, this misunderstanding has to be solved immediately once the patient is admitted to the hospital. Therefore, doctors, nurses and therapist should explain the prognosis of hip fractures explicitly to avoid unrealistic expectations. Although they may not be able to accept the reality in the very beginning, this fact has to be repeatedly reinforced during the hospitalisation.

ii. Contradictory information

Another common problem is the inconsistent information received from different specialties. This may be partly due to the lack of communication between different specialties. This may also be partly due to the lack of experience among some of the junior staff. The former is solved by the common agreement during the meetings of the clinical pathway working group. The latter one is solved by giving the patient and patient family a fact sheet. The fact sheet includes information about average length of stay, the weight bearing status after the operation and the common complications regarding surgery and anaesthesia etc.

iii. Social problems

This is probably the most difficult problem to tackle. It can involve family background, living conditions, family support, availability of carer and financial difficulties. The problems can be very diversified. Three key elements are required to solve the problem: (1) early identification, (2) continuous reassessment, and (3) follow-up of management. Since many of the social problems may not reveal themselves until the patients are ready to be discharged, the problems has to be identified proactively. Our medical social worker played a very important role. Now, $100 \%$ of our patients and over $90 \%$ of their families are interviewed by medical social worker once they are admitted. The problems identified are investigated preliminarily, and possible solutions are 
suggested to the patients' families. The problems and the progress are recorded in a summary sheet. This is transferred to the convalescence hospital together with other discharge information. These pieces of information will be followed up by the medical social workers in the convalescence hospital. No time or resources will be wasted because of repetitive work. Any living condition problems will also be identified and investigated by our occupational therapists. Physiotherapists will help to maximise their walking ability to meet the living conditions. The nurses and doctors will coordinate every aspect to formulate the optimal discharge plan. Nevertheless, this is easier said than done.

iv. Medical problems

Comorbidities are common in elderly hip fracture patients [4]. These are related to postoperative complications. In our series, only 5\% of patients have no comorbidities. Adjusting the medications according to post-operative state and follow-up of these patients are sometimes difficult. These comorbidities are comanaged with the geriatricians in the convalescence hospital. The follow-up and monitoring of the patients before they are discharged are as important as the physical rehabilitation of the patients.

\section{Results and statistics}

Since the beginning of our pathway in early 2007, data has been collected and analysed to monitor our result and progress. In our hospital, the total number of hip fracture analysed since 2007 till end of 2009 is 964 patients. The mean age is 83 . The male to female ratio is $1: 2.8$. The numbers of left and right fractures are nearly the same.

Concerning the pre-operative status of these patients, the American Society of Anaesthesia (ASA) score is used to assess these patients, ranging from 1 to 4 where 1 is most healthy and 4 is anaesthetically unfit. We have $<3 \%$ of patients which belong the ASA 1. Between $46 \%$ were ASA 2 and the others, $52 \%$ were ASA 3 . Only $3 \%$ of patients were recorded to be completely healthy when they are admitted to the hospital. About half of the patients had three or more comorbidities. The commonest comorbidities are hypertension, diabetes and dementia.

Regarding the fracture patterns, $49 \%$ are femoral neck fractures. The other $49 \%$ are intertrochanteric fractures and the remaining $2 \%$ sub-trochanteric fractures. Cannulated screws fixation was done in $16 \%$ of patients. The remaining
$27 \%$ of patients had hemiarthroplasty done. There was an increase of using cephalomedullary device in recent years. Eight percent of patients had cephalomedullary device fixation in 2007 and the number was increased to $22 \%$ in 2009. This was also reflected in the general decrease in use of dynamic hip screw from $45 \%$ in 2007 to $35 \%$ in 2009 . After the operation, $72 \%$ did not need any blood transfusion. The rest needed less than 2 units of blood transfusion.

Among these patients, about $70 \%$ come from home and the rest come from old age home or nursing home. Regarding the walking ability, unaided walker before the operation comprised $37 \%$ of patients. Majority of these patients, $56 \%$, already needs walking aids before surgeries. Others are mainly chair-bound.

While we need to predict the prognosis of the hip fracture patients, besides assessing the premorbid physical state of the patient, the mental state and the ability to take care of themselves are also very important [6]. MMSE is used to assess the mental state of the patients. In the last 3 years, the statistics remain static. About $56 \%$ failed the MMSE which means score was less than 18 . Regarding the MBI score, $43 \%$ of them are completely independent. It reflects many of these patients need some kind of help during their daily lives.

One of the main goals of our clinical pathway is to improve the hospital length of stay in both acute and convalescence hospital. As previously mentioned, the average pre-operative length of stay in 2006 is 6.1 days. After the implementation of the pathway, it drastically shortened the length of stay to 2.53 days in 2007 and 1.42 days in 2009. The post-operative length of stay and the total length of stay were also decreased to 5.54 and 6.66 days, respectively (Fig. 2). With regards to the length of stay of convalescence hospital, there was also a drastic decline from the around 40 days in 2006 to 22.8 days in 2009 (Fig. 3).

The implementation of clinical pathway also improved the incidence of hospital acquired pressure sore. The incidence decreased from $4.3 \%$ to $0.3 \%$ from 2007 to 2009 .

The 30 days mortality rate was also significantly decreased and was kept at a low level compared with international standard $[4,6]$. Our mortality rate was $1.67 \%$ in 2009. The rate in 2007 and 2008 are $1.7 \%$. The 28 days re-admission rate after discharge from hospital remains static at $15 \%$. Among these patients, about $64 \%$ are medical problems related.

In 2006, the infection rates of the internal fixation and hemiarthroplasty were $0.81 \%$ and $2.61 \%$, respectively. This infection rate was reduced and kept low since 2007. The infection rate of internal fixation was kept at $0 \%$ in 2008 and 2009. The infection rate of hemiarthroplasty was also reduced to $0.98 \%$ in 2009 (Fig. 4).

Regarding the social aspect of these hip fracture patients, the difficulties lie in the multiple factors that cause delay in 


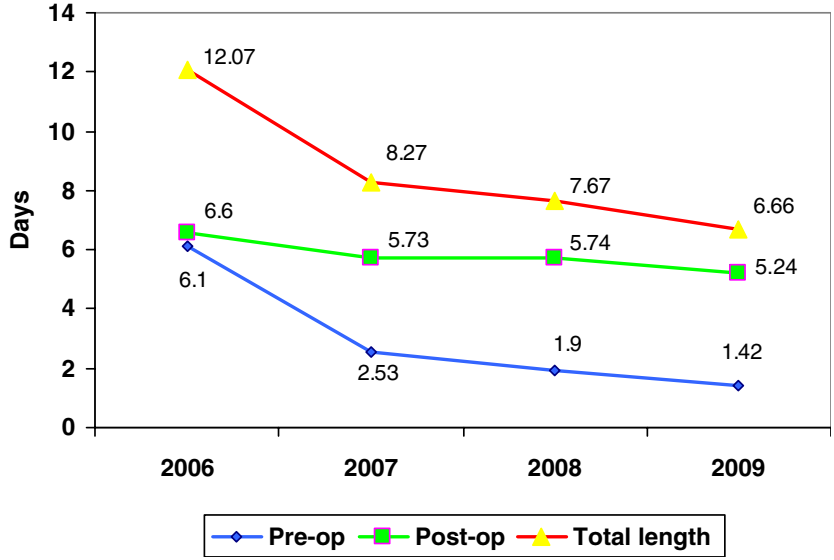

Fig. 2 Length of stay in acute hospital

discharge and rehabilitation. Medical social workers are very helpful in this aspect. Since the start of the clinical pathway, over $99 \%$ of the hip fracture patients were assessed and helped by medical social workers. Together with the effort from nurses and therapist, we are able to discharge $81 \%$ of the patients back to their premorbid living environment (Fig. 5). Besides, a lot of post discharge help care providers are involved in the initial re-integration of the patients back to the society, for example, day care centres, geriatric day hospitals, maid care, non-government organisations or combination of the above.

\section{Discussion}

Our hospital is one of the first to adopt a multidisciplinary approach to manage the geriatric hip fracture patients from acute hospital to convalescence hospital in Hong Kong and probably in Asia as well. The patients are taken care of by different professions using a systematic approach from the minute when they are admitted through the accident and emergency department till they walk out the door of the rehabilitation hospital.

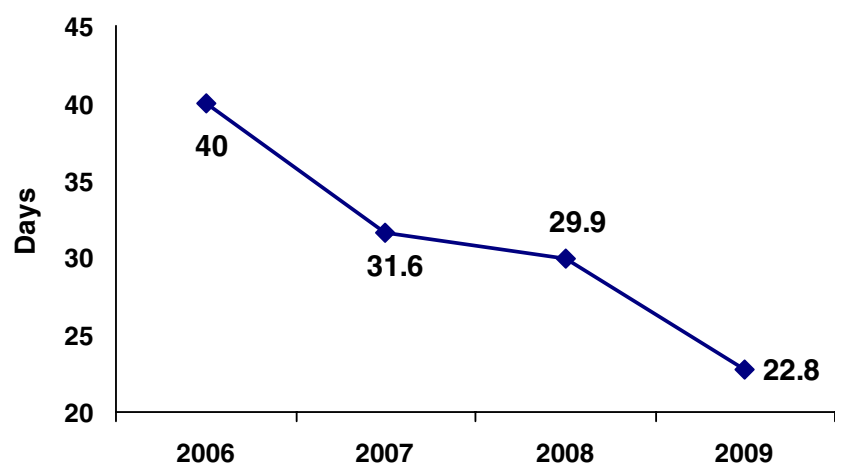

Fig. 3 Length of stay in convalescence hospital

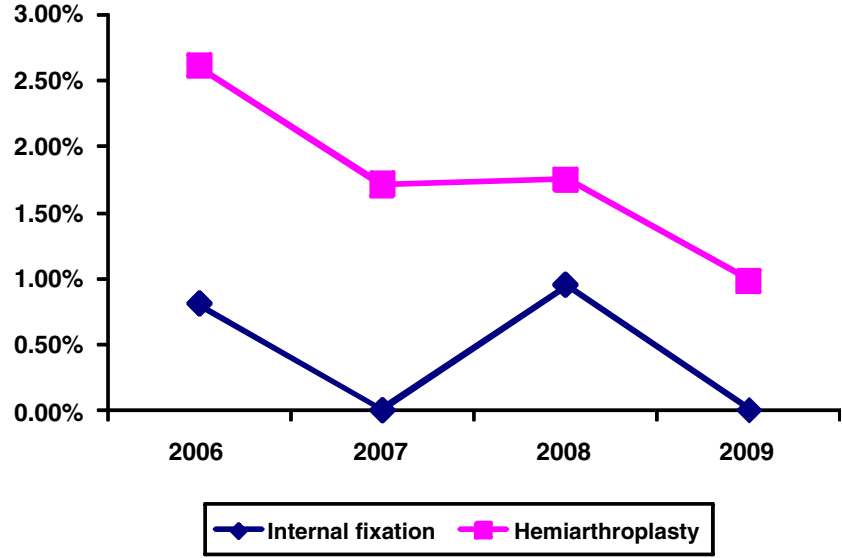

Fig. 4 Surgical site infection rate

In 2009 , there were more than 4,400 hip fractures operated in Hong Kong. In average, $68 \%$ of the patients were operated within 2 days after admission. In our hospital, we have $86 \%$ of our patients operated within 2 days after admission. This is, to our understanding, one of the best performances in our locality. Moreover, the hip fractures are only operated in day time. Furthermore, this pre-operative shortened length of stay also indirectly relates to a similar shortening of total length of stay in acute hospital. Although there is still a lot of debate on the timing of surgery relating to mortality, hip fracture outcome or complications, we are confident that shortening the preoperative stay by better communication between surgeons, anaesthetists and physicians, more efficient use of resources and better monitoring of the system will, by simple logic, improve the outcomes and decrease the suffering of our patients.

According to our data, there is a general trend of increasing age in our hip fracture patients. The average age in 2007 was 82 , in 2008 , it was 83 and in 2009 , it was

\section{Discharge placement}

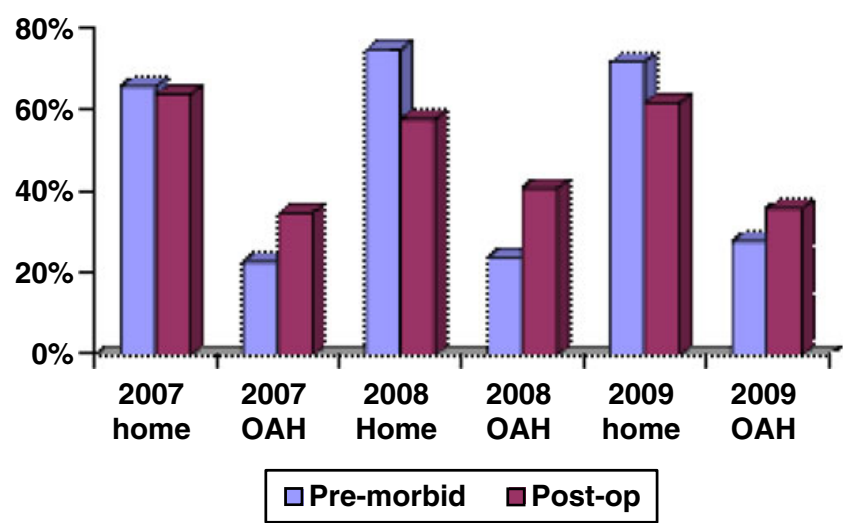

Fig. 5 Placement after discharge from hospital 
84. We do not expect it to have an annual increase but it may represent that we may need to deal with older and older patients and thus more comorbidities in the future. In the mean time, the commonest comorbidities are hypertension and diabetes. Although they are not serious problems, these usually result in other more significant problems like heart problems, cerebral vascular problems, etc. And the need of involvement of geriatrician seems to be one of the important issues in the future development of a better clinical pathway.

We observed that there is a general trend of increasing use of cephalomedullary device on trochanteric fractures in recent years. The use was nearly threefold in 2009 when compared with the data in 2007. Probably this is because of the introduction of concept of inadequate lateral wall buttress in trochanteric fracture. These fractures may have excessive collapse when they are fixed with sliding hip screws. As a result, they may have cut-out of the lag screws. However, the use of these nails in unstable A2 (AO/OTA classification) fractures was controversial [16, 17]. Nevertheless, in some of these $A 2$ fractures, when the lateral walls look flimsy under fluoroscopy, many surgeons would tend to use nails for fixation. This trend may not continue when some more evidence comes up in the future.

One of the most significant improvement in our care after the implementation of the pathway is the significant shorten pre-operative length of stay in acute hospital and the total length of stay of both acute and convalescence hospitals. The average pre-operative length of stay in our hospital was 1.4 days in 2009. This definitely decreases the suffering of the patients as this greatly minimised the pain and distress cause by the unstable hip fractures when they are nursed in the beds. On the other hand, the 28 days mortality also showed a general decrease in the last 3 years. Despite the general increase in age each year, complications like pressure sore, wound infections, chest infection and urinary tract infections are also decreased.

Besides the improved clinical outcome of the patients, the marked shortening of stay also has a strong positive effect on the cost of management. This clinical pathway only utilises the available human and material resources. A case manager, who is a full time nurse, is the additional staff that was created because of the clinical pathway. One case manager can take care of 2-3 clinical pathways at the same time. The average reduction of five patients per day for each patient in acute hospital implies a significant of reduction of cost of care. The cost of care of a hip fracture patient in acute hospital is around US $\$ 400$ each day. About 400 cases are admitted each year; the savings in each year is about US $\$ 800,000$ in acute hospital. On the other hand, this reduction of cost also continues in the rehabilitation hospital.

Discharge problem, in our opinion, is the second most complicated issue in hip fracture patients, which is just followed by the pre-operative assessment issue. This has to be solved by multidisciplinary approach as well. Medical social workers, physiotherapist, occupational therapist, nurses and doctors have to be involved in the planning of discharge when the patient is admitted. In fact, all the preoperative assessment, surgical procedures, rehabilitation and care arrangement are designed to maximise the patient ability to return to their previous premorbid level and placement as soon as possible. However, this is an idealistic statement and the truth is most of the time, these patients have some disability afterwards. Nevertheless, we are proud to say that most of our patients can return to their original living place when they are discharged. Only about $10 \%$ of the patients need to have their placement re-arranged which is mostly because their home environment, even after support and adjustment, becomes unsafe for them to return.

\section{Conclusion and way forward}

The introduction of the geriatric hip fracture clinical pathway in early 2007 was initially started because of the need to control the foreseeable increase in resources spent on these fractures in the coming 10 years. However, many of the orthopaedic colleagues still think that these fractures should have a less priority than the fractures in the young ones and these old people outcome can never be improved by simple measures. Physicians and anaesthetists still think that these elderly patients need to be "fit for surgery" in the same way as elective surgeries. Nevertheless, these misconceptions had been clarified as the clinical pathway progressed. We believe optimization of general condition and early fixation and the multidisciplinary approach to tackle the problems have led to the low mortality rate and complication rate, as well as the significantly shortened length of hospital stay. The results in the past 3 years are not only encouraging but also lead us to believe that the cost of care and the quality of care are not mutually exclusive. Finally, we are sure that there is still room for further improvement. We hope that the present model can be used as reference for other centres with similar health-care setup in their effort to improve the care of the fractures in the elderly.

Acknowledgements The authors would like to thank Ms. So-man Wong, specialty nurse, and Ms. Pearl Chan for their dedication to the preparation of the data and statistics.

Conflicts of interest Dr. Leung is the speaker for Synthes and has received research support from Synthes. None of the other authors has a real or perceived conflict of interest or a disclosure of any personal or financial support.

Open Access This article is distributed under the terms of the Creative Commons Attribution Noncommercial License which permits any noncommercial use, distribution, and reproduction in any medium, provided the original author(s) and source are credited. 


\section{References}

1. Brainsky A, Glick H, Lydick E et al (1997) The economic cost of hip fractures in community-dwelling older adults: a prospective study. J Am Geriatr Soc 45:281-287

2. Johnell O, Kanis J (2005) Epidemiology of osteoporotic fractures. Osteoporos Int 16:S3-S7

3. Donald IP, Bulpitt CJ (1999) The prognosis of falls in elderly people living at home. Age Ageing 28:121-125

4. Roche JJ, Wenn RT, Sahota O, Moran CG (2005) Effect of comorbidities and postoperative complications on mortality after hip fracture in elderly people: prospective observational cohort study. BMJ 331(7529):1374

5. Beaupre LA, Cinats JG, Senthilselvan A, Lier D, Jones CA, Scharfenberger A, Johnston DW, Saunders LD (2006) Reduced morbidity for elderly patients with a hip fracture after implementation of a perioperative evidence-based clinical pathway. Qual Saf Health Care 15(5):375-379

6. Friedman SM, Mendelson DA, Kates SL, McCann RM (2008) Geriatric co-management of proximal femur fractures: total quality management and protocol-driven care result in better outcomes for a frail patient population. J Am Geriatr Soc 56 (7):1349-1356, Epub 2008 May 22

7. Novack V, Jotkowitz A, Etzion O et al (2007) Does delay in surgery after hip fracture lead to worse outcomes? A multicenter survey. Int J Qual Health Care 19:170-176

8. Zuckerman JD, Skovron ML, Koval KJ et al (1995) Postoperative complications and mortality associated with operative delay in older patients who have a fracture of the hip. J Bone Joint Surg Am 77:1551-1556

9. Bottle A, Aylin P (2006) Mortality associated with delay in operation after hip fracture: observational study. BMJ 332:947951

10. Rogers FB, Shackford SR, Keller MS (1995) Early fixation reduces morbidity and mortality in elderly patients with hip fractures from low-impact falls. J Trauma 39:261-265

11. Grimes JP, Gregory PM, Noveck H et al (2002) The effects of time-to-surgery on mortality and morbidity in patients following hip fracture. Am J Med 112:702-709

12. British Orthopaedic Association (2007) The care of fragility fracture patients. British Orthopaedic Association, London

13. Morrison RS, Magaziner J, Gilbert M, Koval KJ, McLaughlin MA, Orosz G, Strauss E, Siu AL (2003) Relationship between pain and opioid analgesics on the development of delirium following hip fracture. J Gerontol A Biol Sci Med Sci 58(1):76-81

14. Sim W, Gonski PN (2009) The management of patients with hip fractures who are taking Clopidogrel. Australas J Ageing 28(4):194-197

15. Court-Brown CM, Caesar B (2006) Epidemiology of adult fractures: a review. Injury 37(8):691-697, Epub 2006 Jun 30

16. Barton TM, Gleeson R, Topliss C, Greenwood R, Harries WJ, Chesser TJ (2010) A comparison of the long gamma nail with the sliding hip screw for the treatment of AO/OTA 31-A2 fractures of the proximal part of the femur: a prospective randomized trial. $\mathrm{J}$ Bone Joint Surg Am 92(4):792-798

17. Parker MJ, Handoll HH (2008) Gamma and other cephalocondylic intramedullary nails versus extramedullary implants for extracapsular hip fractures in adults. Cochrane Database Syst Rev 16(3):CD000093 